NBER WORKING PAPER SERIES

\title{
THE EFFECTS OF PRICES AND POLICIES \\ ON THE DEMAND FOR MARIJUANA: EVIDENCE FROM THE NATIONAL HOUSEHOLD SURVEYS ON DRUG ABUSE
}

\author{
Matthew C. Farrelly \\ Jeremy W. Bray \\ Gary A. Zarkin \\ Brett W. Wendling \\ Rosalie Liccardo Pacula \\ Working Paper 6940 \\ http://www.nber.org/papers/w6940 \\ NATIONAL BUREAU OF ECONOMIC RESEARCH \\ 1050 Massachusetts Avenue \\ Cambridge, MA 02138 \\ February 1999
}

This work was supported by a grant from the National Institutes on Drug Abuse (DA11297-02) and the Substance Abuse and Mental Health Services Administration contract number 283-93-5409. The authors wish to thank Frank Chaloupka for providing alcohol price data and Joanne Kempen for editorial assistance. The views expressed here are those of the author and do not reflect those of the National Bureau of Economic Research.

(C) 1999 by Matthew C. Farrelly, Jeremy W. Bray, Gary A. Zarkin, Brett W. Wendling, and Rosalie Liccardo Pacula. All rights reserved. Short sections of text, not to exceed two paragraphs, may be quoted without explicit permission provided that full credit, including ${ }^{\circledR}$ notice, is given to the source. 
The Effects of Prices and Policies on the Demand

for Marijuana: Evidence from the National

Household Surveys on Drug Abuse

Matthew C. Farrelly, Jeremy W. Bray, Gary A. Zarkin,

Brett W. Wendling, and Rosalie Liccardo Pacula

NBER Working Paper No. 6940

February 1999

JEL No. I18

\begin{abstract}
Recent studies have shown that efforts to curb alcohol use by increasing the price of alcohol and limiting youth's access have succeeded, but they may have had the unintended consequence of increasing marijuana use. This possibility is troubling in light of a recent government report that shows that marijuana use among teens more than doubled between 1990 and 1997. What impact will the proposed large increase in cigarette prices have on the demand for other substances such as marijuana? To better understand how the demand for marijuana responds to changes in the policies and prices that affect its use, we explore the National Household Survey on Drug Abuse (NHSDA). Overall, we find that marijuana, alcohol, and tobacco are complements, so that increasing the price of any one will decrease the demand for marijuana. The results of this paper will help guide the creation of comprehensive policies that curb the use of marijuana in two ways: first, they quantify the effects of policies aimed at curbing the use of each substance, allowing policymakers to evaluate alternative policy options; and second, they clarify the dynamics and interactions between alcohol, tobacco, and marijuana use in response to government policies.
\end{abstract}

Matthew C. Farrelly

Center for Economic Research

Research Triangle Institute

3040 Cornwallis Rd.

Research Triangle Park, NC 27709

mcf@rti.org

Gary A. Zarkin

Center for Economic Research

Research Triangle Institute

3040 Cornwallis Rd.

Research Triangle Park, NC 27709

gaz@rti.org

Rosalie Liccardo Pacula

RAND

1700 Main St.

P.O. Box 2137

Santa Monica, CA 90407

and NBER

pacula@rand.org
Jeremy W. Bray

Center for Economic Research

Research Triangle Institute

3040 Cornwallis Rd.

Research Triangle Park, NC 27709

bray@rti.org

Brett W. Wendling

Center for Economic Research

Research Triangle Institute

3040 Cornwallis Rd.

Research Triangle Park, NC 27709

wendling@rti.org 


\section{INTRODUCTION}

Marijuana use among youths continues to rise despite community, state, and national efforts to educate and inform individuals of the harmful effects of drug use and abuse. For example, between 1990 and 1997 marijuana use among 12- to 17-year-olds more than doubled, increasing from $4.4 \%$ to $9.7 \%$ (U.S. DHHS, 1998). The dramatic increase in marijuana use poses new challenges to decision-makers developing policies to curb drug use among youths. Further complicating efforts to create effective drug control policies are cross-sectional studies that show an interdependence between alcohol and marijuana use (DiNardo and Lemieux, 1992; Chaloupka and Laixuthai, 1997; Pacula, 1998; Model, 1993). The results of these studies emphasize the importance of understanding the interdependence of widely used substances such as alcohol, tobacco, and marijuana and suggest that policies affecting one substance may have unintended consequences on the others. Understanding these interdependencies is especially relevant in light recently announced $\$ 0.45$ per pack cigarette price increase (announced in November, 1998 in response to a $\$ 206$ billion tobacco industry settlement with 46 states). Policymakers want to know whether proposals intended to reduce smoking or drinking among youth have unintended consequences among youth and the general population that may cause marijuana use and other substance use to rise.

The goal of this paper is to further explore these interdependencies using a rich database on drug use - the National Household Survey on Drug Abuse (NHSDA), a nationally representative survey of the U.S. noninstitutionalized population age 12 and older. The detailed questions on substance use contained in the NHSDA allow us to better understand how marijuana use responds to changes in policies that affect the price and availability of marijuana, alcohol, and tobacco. We focus our analyses on two age groups of interest-youths age 12 to 20 and adults age 21 to 30 . We make these age distinction for several reasons. Recent trends show dramatic changes in marijuana use for youths age 12 to 20. Also, many children first experiment with alcohol, tobacco, and marijuana in their teens. Finally, the age 21 cutoff is logical for alcohol because it is the legal drinking age in all states for the years of this study, 1990-1996. We perform parallel analyses for youths and adults.

The specific aim of this paper are to estimate the demand for marijuana for youths and adults as a function of the policies and prices that affect its use. Often times empirical demand models of marijuana use are not a function of own-prices because marijuana prices are not consistently available. In the absence of the price of marijuana, much of the literature (discussed below) includes policies that proxy for the price of marijuana. We follow the practice of including policies as a proxy for price. These policies include the fraction of police arrests that 
are for marijuana possession (i.e., do increased police efforts raise the price of using marijuana and discourage use?); and state marijuana laws that specify fines and jail sentences for possession; state-level marijuana eradication programs aimed at reducing the availability of marijuana (as measured by state-level marijuana eradication programs funded by the Drug Enforcement Administration [DEA]). We also include prices for alcohol and tobacco to capture the possibility that these substances are economic complements or substitutes. In addition, because of our concern that unobservable state-level variables may bias the coefficients on the policies and price variables, all models include state fixed effects.

The results of this paper will help guide the creation of comprehensive policies that curb the use of marijuana in two ways. First, we quantify the effects of policies aimed at curbing the use of marijuana, allowing policymakers to evaluate alternative policy options. For example, we provide estimates of the impact of police efforts to enforce marijuana possession laws and the DEA's Domestic Cannabis Eradication/Suppression Program (hereafter called the Cannabis Eradication Program). The latter program funds states to reduce the supply of marijuana grown in their states by identifying and eradicating marijuana greenhouses, cultivated plots, and wildgrowing marijuana, or "ditchweed." Second, we present results that clarify the interdependencies between the demand for of alcohol, tobacco, and marijuana use. With an understanding of these interdependencies, policymakers can take into account how policy changes directed at one substance affects the demand other substances.

\section{PREVIOUS STUDIES}

In this section we discuss the previous studies that have examined the interdependence of alcohol, cigarette, and marijuana demand. Although most research on this topic has focused on youths, a few studies have examined the general population. In general, this literature has found conflicting results regarding the interdependence of alcohol, cigarette, and marijuana demand.

DiNardo and Lemieux (1992) were the first to analyze the joint demand for both alcohol and marijuana. Using state-level tabulations from Monitoring the Future (MTF) — an annual survey of high school seniors - the authors show that increases in the minimum legal drinking age (MLDA) decreased alcohol consumption among youths but also had the unintended consequence of increasing marijuana use.

Chaloupka and Laixuthai (1997) applied a similar approach to DiNardo and Lemieux's (1992) using individual level data from the 1980-1989 MTF surveys. Because of confidentiality concerns over marijuana use data, Chaloupka and Laixuthai were not able to estimate marijuana 
use data, but they were able to estimate the effect of marijuana decriminalization laws and marijuana prices on alcohol consumption. Their results suggest that marijuana decriminalization leads to large and statistically significant decreases in the frequency of alcohol use, implying that youths switched from alcohol to marijuana. However, combining data on the wholesale and retail price of marijuana for 1989 from the DEA's STRIDE database with the 1989 cross-section of the MTF survey led to mixed results. The authors found that increases in the wholesale price of marijuana led to increases in the frequency of alcohol use, whereas increases in the retail price of marijuana led to decreases in alcohol use.

Thies and Register (1993) were the first to use individual-level data to describe how marijuana and alcohol use changes in response to policy changes. Using data from the National Longitudinal Survey of Youth (NLSY), the authors' showed the minimum legal drinking age laws and marijuana decriminalization laws did not have a statistically significant effect on alcohol or marijuana use. Their study did not include prices for marijuana or alcohol in either the alcohol or marijuana use equations.

In her analysis of hospital emergency room drug episode cross-sectional data (collected by the Drug Abuse Warning Network, or DAWN), Model (1993) reports that alcohol and marijuana are substitutes. The author finds that emergency room episodes involving alcohol were significantly lower in states where marijuana is decriminalized than in those where it was not. This finding suggests that, because the penalties for possessing marijuana are lower in decriminalized states, individuals switched from consuming alcohol to marijuana. Model also finds more marijuana-related episodes in decriminalized states.

More recently, Pacula (1998) uses the 1984 wave of the NLSY to estimate the joint demand for both alcohol and marijuana using a sample of roughly 5,000 individuals. Pacula estimates both alcohol and marijuana demand directly and shows that increasing beer taxes decreases the prevalence and consumption of alcohol and decreases the prevalence of marijuana use. The minimum legal drinking age also decreases the prevalence of alcohol use but has no effect on the prevalence of marijuana use.

A study by Saffer and Chaloupka (1998) analyzes the demand for alcohol, marijuana, cocaine, and heroin for individuals of all ages using the 1988, 1990, and 1991 NHSDAs. The authors estimate the demand for marijuana as a function of marijuana decriminalization laws, similar to that used by Chaloupka and Laixuthai (1997), however, they do not include marijuana prices. Their results show that marijuana decriminalization increases the probability that an individual consumes marijuana by $4 \%$ to $6 \%$. The authors also examine own- and cross-price 
effects for the demand for alcohol, heroin, and cocaine. They found increases in the price of alcohol lead to decreases in marijuana use in the past month. Overall, their findings are similar to those found in this study that alcohol and illicit substances are economic complements.

Finally, Chaloupka, Pacula, Farrelly, Johnston, O’Malley, and Bray (1998) examine the relationship between marijuana and tobacco use by 8th-, 10th-, and 12th-graders from the 19921994 MTF cross-sectional data. The authors find that jail sentences, fines and the price of cigarettes did not have a statistically significant impact on the probability of marijuana use. However, they find that youths are more likely to use marijuana and to use marijuana more frequently if they live in a state that has decriminalized the possession of small quantities of marijuana. Because of the short timeframe, the authors did not include state fixed effects because there was not enough variation within states over time to identify price/policy effects in this time period. However, there was a statistically significant negative relationship between the amount of marijuana consumed by current users of marijuana and the price of cigarettes and fines for marijuana possession. These results suggest that marijuana and tobacco are economic complements.

In summary, the results of these studies emphasize the importance of understanding the interplay among policies that affect marijuana, alcohol, and tobacco. However, no clear consensus has emerged from these studies, perhaps because of limitations in the availability of appropriate data. Another explanation for why there is no clear consensus in the literature is the failure in all existing studies to control for unobserved state-specific characteristics. Several studies rely on an indicator variable for states in which marijuana is decriminalized without controlling for state fixed effects. It is not clear whether this indicator variable is detecting the impact of the laws on use or other state-specific characteristics that may be correlated with use, such as the willingness to accept alternative behaviors or lifestyles. Because other price and policy variables used in the literature are measured at the state level, these too may capture unobserved characteristics of the state. Failing to control for these unobserved characteristics may bias the estimate of the effects of all state policy and price variables.

The analyses presented below address both of these issues. We first estimate the demand for marijuana as a function of the state marijuana possession fines and jail sentences, police enforcement, and the Cannabis Eradication Program mentioned above (and described in more detail below) as reported by the DEA. The data for this program are reported annually for each state and vary both over time and over states. We include state fixed effects to control for unobserved state-level characteristics in all models. By including these fixed effects, we are able 
to distinguish the effects of unobserved state characteristics from the effects of state policies and prices.

\section{DATA}

In this study, we used data from the NHSDA. The NHSDA, an annual survey that began in 1971, has become a key national indicator of the nation's drug use behavior and problems. The National Institute on Drug Abuse (NIDA) sponsored the NHSDA from 1974-1992 and SAMHSA has sponsored the surveys since 1992.. The NHSDA is designed to provide data on the extent of drug use and abuse by the noninstitutionalized civilian population age 12 and older in the United States (SAMHSA, 1992; 1994).

We combined 1990-1996 NHSDA data to provide estimates of the own- and cross-price and policy effects on the demand for marijuana. In all 6 years, the NHSDA used identical survey questions for the prevalence of past-year and past-month use of marijuana and the same fivestage area probability sample design. The NHSDA was revised in 1994, resulting in some noncomparability of pre- and post-1994 estimates, particularly tobacco use. For this reason, we do not explicitly model cigarette demand in this paper. Sampling weights were computed based on the probability of selection at each stage, and these weights were used in all analyses.

Because of the sensitive nature of the survey topic, self-administered answer sheets were used for marijuana use questions to increase the confidentiality and anonymity of the respondents' answers. This format was designed to minimize underreporting of substance use, which is a potential limitation of self-reported surveys (Hoyt and Chaloupka, 1993). In a 1990 field test of various survey instruments, Turner, Lessler, and Devore (1992) found that the selfadministered format of the NHSDA decreases the underreporting of substance use compared to an interviewer-administered format.

Although the NHSDA is the only survey that provides detailed and consistent data on drug use among members of the household population in the coterminous United States, the NHSDA has a number of limitations. First, as mentioned above, the data are self-reports of drug use, so their value depends on respondents' truthfulness and memory. Although the selfadministered format of the NHSDA decreases the underreporting of substance use in general, any given individual's propensity to report substance use may be affected by the degree of privacy during the interview. To examine the sensitivity of our results to the degree of privacy, we include the interviewer's report of the degree of privacy during the interview as a supplemental covariate in our demand equations. 
Second, the survey is cross-sectional rather than longitudinal. Thus, individuals are interviewed only once and are not followed for additional interviews. The surveys therefore provide an overview of the prevalence of drug use at specific points in time rather than a view of how drug use changes over time for groups of individuals. Therefore, conclusions about the relationship between marijuana use and the policies and prices that affect its use should be interpreted carefully. The results presented below should be considered correlational rather than causal.

Third, a small proportion (roughly 1\%) of the U.S. population is excluded from the surveys. With the exception of 1991, the subpopulations excluded are those residing in noninstitutional group quarters (e.g., military installations, college dormitories, group homes), those in institutional group quarters (e.g., prisons, nursing homes, treatment centers), and those with no permanent residence (e.g., the homeless and residents of single rooms in hotels). In 1991, the target population was extended to all 50 states and included residents of noninstitutional group quarters and civilians living on military bases. If the drug use of excluded groups differs from that of the household population, the NHSDA may provide slightly inaccurate estimates of drug use in the total population. This may be particularly true for the homeless and prison populations.

\section{ANALYSIS VARIABLES}

The dependent variable used in our analyses is an indicator variable for any past-month use of marijuana. The demographic controls used in our analyses are all self-reported measures from the NHSDA public use files. These controls consist of gender, age, number of people living in the household, number of children under age 12 in the household, marital status, race, family income, current school enrollment status, education, and size of the MSA of residence. In addition to these self-reported variables, we also included two interviewer-reported variables: urban/rural status of the respondent's current residence and an indicator for the degree of privacy during the interview.

In addition to the data contained in the NHSDA, we included state-level information on prices and policies that affect the use of marijuana, which were merged with the NHSDA. The data include the prices of alcohol and tobacco, arrest information on alcohol and marijuana violations, and other marijuana enforcement activities.

Specifically, we included data from the Cannabis Eradication Program from the DEA. This program is funded by the DEA and is operated as a partnership between DEA and state and 
local agencies to reduce the supply of marijuana. The eradication program eliminates both wildgrowing marijuana ("ditchweed") and cultivated marijuana grown in greenhouses and tended plots. We focused on the annual number of cultivated plants that are eradicated in each state because ditchweed often has much less tetrahydracannabinol (THC), the psychoactive component in marijuana. To create a more uniform statistic that can be compared from state to state, we adjusted the number of cultivated plants by each state's population to create the number of plants eradicated per million residents. Ideally, to be able to interpret this variable as a proxy for the price of marijuana we would like information on the proportion of the total marijuana supply that is eradicated. Unfortunately, information on supply is not available and therefore our ability to proxy for price is limited. In absence of information on total supply, it is possible that in years when supplies are abundant, the amount eradicated increases but the amount eradicated as a proportion of total supply may decrease (and hence the price would decrease).

We also gathered arrest information from the Uniform Crime Reports for 1990-1996. These data include the number of marijuana possession violations, public drunkenness violations, and total arrests at the county level. These data were then aggregated to the state level. However, because not all counties and not all areas within counties report arrest data, we also included a coverage indicator that represents the fraction of the state that reports arrest data. Because increases in marijuana and alcohol violations may simply be a function of increased use, we divided the number of possession/drunkenness arrests by the total number of arrests as a proxy for enforcement effort.

We also have state marijuana law data on fines and jail terms for various quantities of marijuana possession for 1991-1994 and 1996 that we collected from state legal codebooks. The marijuana possession laws specify the maximum and minimum jail terms and penalties for varying amounts of possession. In other words, states usually specify fines and penalties for an ounce of marijuana and then another set of penalties for some larger quantity. We characterize these data by including the minimum fine for any positive amount of marijuana.

Data on cigarette prices come from the Tax Burden on Tobacco, an annual report from the Tobacco Institute that contains state-level information on state and federal excise taxes and average state cigarette retail prices (Tobacco Institute, 1997).

Alcohol price information comes from the American Chamber of Commerce Research Association's Inter-City Cost of Living Index, a quarterly report of prices for various commodities and services for over 250 cities (1997). From these data we constructed state 
annual average prices of beer, wine, and liquor. Because beer is the most commonly consumed alcoholic beverage, we use the price of beer to proxy for the price of alcohol.

Summary statistics (mean, minimum, maximum, and standard deviation) of both NHSDA survey data as well as state-level policy and price data are listed in Table 1 for both age groups.

\section{METHODS}

This section describes our methodology to study the demand for marijuana using pooled independent cross-sections of the 1990 to 1996 NHSDAs. Because we are concerned with the contemporaneous effects of prices and policies that affect marijuana use, we define current users of marijuana as those who have had any use in the past month.

In this paper we focus on the decision to use marijuana and not the amount or frequency of marijuana use. Future analyses will explore average daily consumption among current users with ordinary least squares regressions. These addition analyses will also include state laws governing the sales of tobacco to minors and other clean indoor air laws as reported by the Coalition on Smoking OR Health's State Legislative Actions on Tobacco Issues. The current analyses include state fixed effects that control for much of this variation across states. This approach follows the "two-part" model that has been used extensively in the health economics field to model the demand for medical care (Duan et al., 1983), smoking (Evans and Farrelly, 1998; CDC, 1998), and drinking (Manning, Blumberg, and Moulton, 1995; Chaloupka and Wechsler, 1996).

To address the impact of prices and policies on the decision to use marijuana, we pose the following demand specification for marijuana:

$$
\operatorname{prob}(\mathrm{M}>0)=\Phi\left(\mathrm{g}_{0}+\mathrm{g}_{1} \mathrm{P}_{\mathrm{M} 1}+\mathrm{g}_{2} \mathrm{P}_{\mathrm{M}} 2+\mathrm{bX}+\text { fYear }+ \text { hState }\right)
$$

where $\mathrm{M}$ is current marijuana use (past 30 days), $\mathrm{X}$ is a vector of sociodemographic variables described above, and $\Phi$ is the standard normal cumulative density function. Because marijuana price data are not consistently reported, we included data on several policies that affect its use. PM1 represents the intensity of marijuana law enforcement and PM2 is the level of state cannabis eradication. We expect the sign of $g_{1}$ to be negative so that as the police focus a greater percentage of their time pursuing marijuana arrests, the less likely individuals will be to consume marijuana. The sign of $\mathrm{g}_{2}$ is ambiguous. Increasing efforts to eradicate fields of marijuana may signal a good growing year or more successful attempts at identifying sources of 
marijuana. In addition, because, unlike alcohol and tobacco where there are state taxes that affect prices, the market for marijuana may easily extend beyond the state.

We then checked the sensitivity of our own-effects results by including cross-price effects for alcohol and cigarettes:

$$
\operatorname{prob}(\mathrm{M}>0)=\Phi\left(\mathrm{g}_{0}+\mathrm{g}_{1} \mathrm{P}_{\mathrm{M}}+\mathrm{g}_{2} \mathrm{P}_{\mathrm{A}}+\mathrm{g}_{3} \mathrm{P}_{\mathrm{C}}+\mathrm{bX}+\mathrm{fYear}+\mathrm{hState}\right)
$$

where $\mathrm{P}_{\mathrm{A}}$ is the price of alcohol and $\mathrm{PC}_{\mathrm{C}}$ is the price of cigarettes. The contemporaneous effects of all prices on the probability of marijuana use are represented in Equation (2). If $g_{2}>0$, those who live in high alcohol-price states are less likely to consume alcohol (all else equal) and are more likely to smoke marijuana. If this is true, then marijuana and alcohol are economic substitutes. However, if taxing alcohol decreases alcohol demand and decreases the demand for marijuana, then $\mathrm{g}_{2}<0$ and the two goods are economic complements. In other words, people who live in high alcohol-price cities/states are less likely to consume alcohol and less likely to consume marijuana.

From both Equations (1) and (2) we constructed demand elasticities for participation (any use) that indicate how sensitive demand is to prices and policies. Although it is not a price elasticity, we calculated elasticities for the Cannabis Eradication Program because having a such a "unitless" measure facilitates comparisons of the results across regressions.

The prevalence and intensity of marijuana use may vary from state to state because of characteristics about the state not captured by the policy variables above. To account for this variation we include state indicator variables or state fixed effects. Analyses without state indicator variables may improperly attribute the effect of policy characteristics about the state not captured in the policy variables. In the absence of state fixed effects the results inferred from state-level data on prices and policies may reflect a combination of both individual state characteristics and the effects of the price and policy variables. The advantage of including state effects in a pooled independent cross-sectional data set is that we control for all unobserved state differences, including attitudes, preferences, and other state idiosyncratic characteristics that may affect demand.

Despite the advantages of including state effects, many previous studies have not included them in addition to state-level prices because of concerns over the amount of withinstate variation in prices and policies over time. Without sufficient variation in the price/policy variables of interest within a state over time, it is not possible to identify both the state-specific effect and the price/policy variable. In response to this concern, researchers have often omitted 
state effects in favor of regional effects. While this is a reasonable approach given data limitations, results from these models should be interpreted carefully. If there is not sufficient variation in the key policy variables of interest, these variables may simply reflect prevailing attitudes and behaviors within a state rather than the behavior changes that are a result of these variables. In this paper we have sufficient variation to include state effects. To make stronger conclusions about the causal relationship between marijuana use and the prices and policies that affect its use requires longitudinal surveys and sufficient variation in prices/policies to determine their effects on marijuana use. In absence of longitudinal individual data on drug use, we feel that cross-sectional pooled across years that include state effects is the strongest approach given these data. To demonstrate the potential sensitivity of results to the exclusion of state effects, we also report the results of models that include only regional effects.

To include the effects of national policies (e.g., changes in the national excise taxes on alcohol, increased national efforts to curb the supply of drugs entering the U.S.) and other secular trends into our analyses, we included year indicator variables in the pooled independent crosssectional data set. Although it is difficult to attribute changes in the national prevalence and intensity of marijuana, alcohol, and tobacco from year to year to specific policy changes, the inclusion of year indicators capture a combination of the effects of national policies and other nationwide secular trends.

\section{RESULTS}

\section{Youths Age 12 to 20}

We first report the results of our models for youths age 12 to 20 . Table 2 shows both the own-effects model and the model that includes own- and cross-price/policy effects (the results for all coefficients are in the appendix). We report the marginal effects, standard errors, and participation elasticities from the probit models. The own-effects model shows that increased police enforcement appears to have no effect on the probability of use among youths. The elasticity is nearly zero and the marginal effect is very imprecisely measured. The marginal effect of the Cannabis Eradication Program implies that it may not serve as a proxy for pricethe elasticity is very small, 0.027 , and statistically significant. Further investigation showed that higher eradication efforts were also not strongly correlated with survey respondents' selfreporting of the difficulty of obtaining marijuana. As a point of comparison for all of these results, Saffer and Chaloupka (1998) show that the effect of decriminalizing marijuana leads to an increase in marijuana use in the past 30 days by $4 \%$. 
When we include prices for beer and cigarettes, there is little change in the own-effects. However, we do find statistically significant effects for these prices. The results indicate that alcohol and cigarettes are economic complements of marijuana. Higher cigarette prices lead to decreased probability of marijuana use among youths, as do higher beer prices. The cross-price elasticity for cigarettes is -0.49 . This falls within the range of estimates obtained by Chaloupka et al. (1998) who use cross-sectional data from the MTF Surveys from 1992-1994 of 8th, 10th, and 12th graders. The NHSDAs also include high school dropouts. The cross-price elasticity of beer is -1.05 . Therefore, recent assertions that raising the price of cigarettes will encourage youths to shift from cigarettes to marijuana is not supported in these data.

\section{Adults Age 21 to 30}

The results for adults age 21 to 30 are quite different from those for youths (see Table 3). The own-effects model shows that increased enforcement of marijuana laws as measured by a greater percentage of total arrests involving marijuana possession is negatively associated with a decreased probability of marijuana use in the past 30 days. This effect, which is statistically significant, yields an elasticity of -0.157 . Thus, if marijuana law enforcement increases by $10 \%$, the probability of marijuana use among adults age 21 to 30 decreases by $1.6 \%$. The results of the Cannabis Eradication Program show a negative and marginally statistically significant relationship to marijuana use. However, as we stated above, it is difficult to interpret a causal relationship between changes in this variable and changes in marijuana use.

When we include price effects for beer and cigarettes, the own-effects remain fairly stable. The participation elasticity for marijuana possession enforcement increases slightly to 0.176. We find no statistically significant cross-price effects for beer and cigarettes, however, the signs indicate a weak complementary relationship.

\section{Marijuana Fines/Penalties}

In addition to the models presented above, we collected data on marijuana fines from various years of the Bureau of Justice Statistics' annual Sourcebook on Criminal Justice Statistics as well as state legal code books. These data are complete for 1991-1994 and 1996. Once again, these results show that the policies directed at curbing marijuana use have no effect on youth marijuana use; however, the cross-price effects remain negative and statistically significant (see Table 4). For adults, we do find a statistically significant relationship between increased median marijuana possession fines and decreased probability of marijuana use. The resulting elasticity is only -0.008 . Therefore, a doubling of the current median fines would 
decrease the probability of marijuana use by $0.8 \%$. Although this effect is small, it is a relatively inexpensive policy to enact. The other effects are very similar to the previous models for adults.

\section{State Versus Regional Effects}

To check the sensitivity of our results to the inclusion of state effects, we re-estimated the models presented in Tables 2 and 3 including 9 census regional effects in place of the state effects. The results from the youth model remained qualitatively the same but the elasticities changed somewhat. More dramatic changes were found in the adult model. The coefficient on the marijuana possession arrest and the cannabis eradication variables changed from negative and statistically significant in the state effects model to positive and statistically insignificant $(\mathrm{P}=0.11$ and $\mathrm{P}=0.35$ respectively). In addition, the coefficient on the price of beer changed signs, but remained statistically insignificant while the coefficient on the price of cigarettes remained positive but was statistically significant. The sensitivity of our results to the inclusion of state effects reinforces our belief that conclusions about policy variables in analyses without state effects may reflect the influence of both individual state characteristics and the effects of the price and policy variables. Therefore, the more conservative approach to determine price and policy effects separately from state characteristics requires that state effects be included in the specification.

\section{DISCUSSION}

Our results suggest that raising the price of alcohol or tobacco decreases the probability of marijuana use among youths, while the policies targeted at curbing marijuana use do not appear to influence marijuana use among youths. A very different pattern emerged for adults who are apparently responsive to both increased police enforcement of marijuana laws and higher fines for marijuana possession. In addition, adults' use of marijuana is responsive to the price of beer and cigarettes. We attribute these differences to several potential factors. Because the costs associated with marijuana possession involve both probability or risk of being caught and a subsequent fine or jail term once caught, youths may perceive these risks and costs differently than adults. First, youths may be less risk-averse than adults and therefore attach a lower cost to a given probability of being caught. Second, youths may discount the future costs and consequences of being arrested at a higher rate than adults. In addition, the consequences of alcohol use change as youths reach the legal minimum drinking age. Finally, youths ages 12-20 are experimenting with alcohol, tobacco, and marijuana more than adults who patterns of consumption may be more stable. 
Although the recently proposed \$1.10-per-pack cigarette price increase directed at curbing teen smoking failed to pass Congress, it is likely that other price increases will be proposed in the future. Even if future legislation does not call for excise tax increases, cigarette prices were recently (November, 1998) increased by $\$ 0.45$ per pack in response a $\$ 206$ billion global tobacco settlement between 46 states' attorney generals and the tobacco industry. Although some have suggested that such price increases may discourage teen cigarette smoking, only to lead to an increase in marijuana use, these fears appear to be unfounded. A \$1.10-perpack increase in the price of cigarettes would lead to roughly a 50\% increase in the current price of cigarettes. Based on our models, such an increase would decrease the probability of marijuana use among youths by roughly $25 \%$. Similarly, alcohol price increases would also discourage marijuana use among youths. However, adult marijuana use does not appear to be sensitive to changes in the prices of cigarettes or alcohol.

Because there is sufficient within-state variation in the prices and policies over time in our sample, we are able to make important policy conclusions. We find that that marijuana, alcohol and tobacco are economic complements for youths and that adults use of marijuana is reduced as police enforcement of marijuana laws is increased. Although these results rely on cross-sectional data, we feel that the inclusion of state specific effects strengthens our results by controlling for other factors (e.g., public sentiment, political environment) 
TABLE 1. DESCRIPTIVE STATISTICS, NHSDA 1990-1996

\begin{tabular}{|c|c|c|c|c|}
\hline \multirow[b]{2}{*}{ Variable } & \multicolumn{2}{|c|}{$\begin{array}{l}\text { Youths Age } 12 \text { to } 20 \\
\quad \mathrm{~N}=49,311\end{array}$} & \multicolumn{2}{|c|}{$\begin{array}{c}\text { Adults Age } 21 \text { to } 30 \\
\quad \mathrm{~N}=44,223\end{array}$} \\
\hline & Mean & Std. Dev. & Mean & Std. Dev. \\
\hline Age & 15.98 & 2.6 & 25.7 & 2.86 \\
\hline Family size & 4.27 & 1.7 & 3.3 & 1.57 \\
\hline Male & $44.0 \%$ & 49.6 & $42.3 \%$ & 49.41 \\
\hline Divorced/separated & $0.4 \%$ & 6.4 & $7.6 \%$ & 26.45 \\
\hline Married & $2.8 \%$ & 16.6 & $46.8 \%$ & 49.90 \\
\hline Widowed & $0.0 \%$ & 1.0 & $0.2 \%$ & 4.06 \\
\hline White & $69.0 \%$ & 46.2 & $71.4 \%$ & 45.2 \\
\hline African-American & $14.7 \%$ & 35.4 & $12.6 \%$ & 33.15 \\
\hline Hispanic & $12.0 \%$ & 32.6 & $11.6 \%$ & 32.04 \\
\hline Other race/ethnicity & $4.2 \%$ & 20.0 & $4.0 \%$ & 19.57 \\
\hline Real family income (1982-1984 dollars) & $\$ 25,625.46$ & $19,957.55$ & $\$ 23,952.69$ & $18,401.59$ \\
\hline Enrolled in school & $58.1 \%$ & 49.3 & $15.3 \%$ & 36.03 \\
\hline High school graduate & $14.8 \%$ & 35.5 & $34.9 \%$ & 47.7 \\
\hline Some college education & $9.2 \%$ & 28.9 & $27.3 \%$ & 44.57 \\
\hline College graduate & $0.2 \%$ & 4.3 & $16.5 \%$ & 37.12 \\
\hline Some graduate school education & $0.0 \%$ & 1.8 & $5.9 \%$ & 23.52 \\
\hline MSA > 1,000,000 & $41.4 \%$ & 49.3 & $46.9 \%$ & 49.90 \\
\hline MSA $250,000-1,000,000$ & $23.6 \%$ & 42.5 & $24.4 \%$ & 42.92 \\
\hline Rural resident & $15.3 \%$ & 36.0 & $13.6 \%$ & 34.30 \\
\hline Neither MSA nor rural & $9.8 \%$ & 29.8 & $7.5 \%$ & 26.29 \\
\hline $\mathrm{MSA}<250,000$ & $9.8 \%$ & 29.8 & $7.7 \%$ & 26.7 \\
\hline $\begin{array}{l}\text { Per capita cultivated marijuana plants } \\
\text { eradicated }\end{array}$ & 21,257 & 53,263 & 21,541 & 51,957 \\
\hline Real price of wine & $\$ 3.57$ & 0.68 & $\$ 3.63$ & 0.70 \\
\hline Real price of beer & $\$ 2.68$ & 0.27 & $\$ 2.67$ & 0.27 \\
\hline Real price of cigarettes & $\$ 1.18$ & 0.14 & $\$ 1.16$ & 0.15 \\
\hline Interview with no significant interruptions & $76.3 \%$ & 42.6 & $82.9 \%$ & 37.66 \\
\hline $\begin{array}{l}\text { Percent of the state population reporting } \\
\text { arrest data }\end{array}$ & $86.5 \%$ & 20.1 & $87.4 \%$ & 19.20 \\
\hline $\begin{array}{l}\text { Marijuana possession arrests as a percentage } \\
\text { of total arrests }\end{array}$ & $2.3 \%$ & 1.5 & $2.4 \%$ & 1.11 \\
\hline Alcohol use in the past month & $30.7 \%$ & 46.1 & $65.3 \%$ & 47.60 \\
\hline Marijuana use in the past month & $8.5 \%$ & 27.9 & $9.9 \%$ & 29.85 \\
\hline Cigarette use in the past month & $20.4 \%$ & 40.3 & $34.2 \%$ & 47.45 \\
\hline
\end{tabular}


TABLE 2. PROBABILITY OF PAST MONTH MARIJUANA USE AMONG 12- TO 20-YEAR-OLDS: OWN- AND CROSS-PRICE/POLICY EFFECTS, NHSDA 1990-1996

Marginal Effect

(Standard Error)

[Elasticity]

\begin{tabular}{lcc}
\hline \hline Policy/Price & Own-Effects & Own- and Cross-Effects \\
\hline Marijuana possession arrests/total arrests & 0.033 & -0.060 \\
& $(0.176)$ & $(0.183)$ \\
Cannabis Eradication Program & {$[\mathbf{0 . 0 0 9}]$} & {$[-\mathbf{0 . 0 1 6}]$} \\
& $1.07 \mathrm{E}-07^{* *}$ & $1.00 \mathrm{E}-07^{* *}$ \\
Real price of cigarettes & $(3.72 \mathrm{E}-08)$ & $(3.76 \mathrm{E}-08)$ \\
& {$[\mathbf{0 . 0 2 7}]$} & {$[\mathbf{0 . 0 2 5}]$} \\
& & $-3.64 \mathrm{E}-04^{*}$ \\
Real price of beer & & $(2.16 \mathrm{E}-04)$ \\
& & {$[-\mathbf{0 . 4 8 6}]$} \\
Observations & & $-0.034^{* *}$ \\
$\mathrm{R}^{2}$ & & $(0.013)$ \\
\hline
\end{tabular}

* Statistically significant at $\mathrm{P}>0.10$

** Statistically significant at $\mathrm{P}>0.05$

*** Statistically significant at $\mathrm{P}>0.01$ 
TABLE 3. PROBABILITY OF PAST MONTH MARIJUANA USE AMONG 21- TO 30-YEAR-OLDS: OWN- AND CROSS-PRICE/POLICY EFFECTS, NHSDA 1990-1996

Marginal Effect

(Standard Error)

[Elasticity]

\begin{tabular}{lcc}
\hline Policy/Price & Own-Effects & Own- and Cross-Effects \\
\hline Marijuana possession arrests/total arrests & $-0.642^{* *}$ & $-0.721^{* *}$ \\
& $(0.297)$ & $(0.301)$ \\
Cannabis Eradication Program & {$[-\mathbf{0 . 1 5 7}]$} & {$[-\mathbf{0 . 1 7 6}]$} \\
& $-8.48 \mathrm{E}-08^{*}$ & $-8.22 \mathrm{E}-08^{*}$ \\
Real price of cigarettes & $(4.54 \mathrm{E}-08)$ & $(4.57 \mathrm{E}-08)$ \\
& {$[\mathbf{- 0 . 0 1 8}]$} & {$[-\mathbf{0 . 0 1 8}]$} \\
& & $4.04 \mathrm{E}-04$ \\
Real price of beer & & $(2.72 \mathrm{E}-04)$ \\
& & {$[\mathbf{0 . 4 7 4}]$} \\
Observations & & 0.010 \\
$\mathrm{R}^{2}$ & & $(0.016)$ \\
\hline \hline
\end{tabular}

* Statistically significant at $\mathrm{P}>0.10$

** Statistically significant at $\mathrm{P}>0.05$

*** Statistically significant at $\mathrm{P}>0.001$ 
TABLE 4. EFFECTS OF MARIJUANA LAW POSSESSION FINES ON THE PROBABILITY OF MARIJUANA USE AMONG YOUTHS AND ADULTS: NHSDA 1991-1994, 1996

\begin{tabular}{|c|c|c|}
\hline \multirow[b]{2}{*}{ Fine } & $\begin{array}{l}\text { Youths Age } \\
12 \text { to } 20\end{array}$ & $\begin{array}{c}\text { Adults Age } \\
21 \text { to } 30\end{array}$ \\
\hline & $\begin{array}{c}\text { Marginal Effect } \\
\text { (standard error) } \\
\text { [elasticity] }\end{array}$ & $\begin{array}{c}\text { Marginal Effect } \\
\text { (standard error) } \\
\text { [elasticity] }\end{array}$ \\
\hline Median fine for initial quantity & $\begin{array}{c}1.75 \mathrm{E}-08 \\
(2.21 \mathrm{E}-08) \\
{[\mathbf{0 . 0 0 2}]}\end{array}$ & $\begin{array}{c}-8.35 \mathrm{E}-08 * * * \\
(3.18 \mathrm{E}-08) \\
{[-\mathbf{0 . 0 0 8}]}\end{array}$ \\
\hline Marijuana possession arrests/total arrests & $\begin{array}{l}-0.223 \\
(0.195) \\
{[-\mathbf{0 . 0 5 8}]}\end{array}$ & $\begin{array}{c}-0.803 * * \\
(0.345) \\
{[-\mathbf{0 . 1 9 6}]}\end{array}$ \\
\hline Cannabis Eradication Program & $\begin{array}{c}-1.35 \mathrm{E}-07 * \\
(0.73 \mathrm{E}-07) \\
{[\mathbf{- 0 . 0 3 3}]}\end{array}$ & $\begin{array}{c}-1.92 \mathrm{E}-07 * * \\
(0.90 \mathrm{E}-07) \\
{[\mathbf{- 0 . 0 4 2 ]}}\end{array}$ \\
\hline Real price of cigarettes & $\begin{array}{c}-6.01 \mathrm{E}-4 * * \\
(2.45 \mathrm{E}-4) \\
{[\mathbf{- 0 . 8 0 2}]}\end{array}$ & $\begin{array}{c}2.92 \mathrm{E}-04 \\
(3.29 \mathrm{E}-04) \\
{[\mathbf{0 . 3 4 3 ]}}\end{array}$ \\
\hline Real price of beer & $\begin{array}{c}-0.036 * * \\
(0.014) \\
{[-\mathbf{1 . 1 0}]}\end{array}$ & $\begin{array}{c}0.025 \\
(0.019) \\
{[\mathbf{0 . 6 6 5}]}\end{array}$ \\
\hline Observations & 38,679 & 33,200 \\
\hline $\mathrm{R}^{2}$ & 0.116 & 0.089 \\
\hline $\begin{array}{ll}* & \text { Statistically significant at } \mathbf{P}>\mathbf{0 . 1 0} \\
* * & \text { Statistically significant at } \mathrm{P}>0.05 \\
* * * & \text { Statistically significant at } \mathrm{P}>0.01\end{array}$ & & \\
\hline
\end{tabular}




\section{APPENDIX: BASIC MODEL WITH OWN- AND CROSS-PRICE/POLICY EFFECTS}

FOR YOUTHS AND ADULTS

\begin{tabular}{|c|c|c|}
\hline Marijuana Use in the Past 30 Days & Youths Age 12 to 20 & Adults Age 21 to 30 \\
\hline Possession arrests/total arrests & $\begin{array}{l}-0.059 \\
(0.183)\end{array}$ & $\begin{array}{c}-0.721 * * \\
(0.301)\end{array}$ \\
\hline Marijuana plants eradicated & $\begin{array}{c}1.00 \mathrm{E}-07 * * * \\
(3.76 \mathrm{E}-08)\end{array}$ & $\begin{array}{l}-8.22 \mathrm{E}-08 \\
(4.57 \mathrm{E}-08)\end{array}$ \\
\hline Public drunkenness arrests/total arrests & $\begin{array}{l}-0.122 \\
(0.340)\end{array}$ & $\begin{array}{l}-0.115 \\
(0.133)\end{array}$ \\
\hline Real price of beer & $\begin{array}{c}-0.034 * * * \\
(0.013)\end{array}$ & $\begin{array}{c}0.010 \\
(0.016)\end{array}$ \\
\hline Real price of cigarettes & $\begin{array}{l}-3.64 \mathrm{E}-04^{*} \\
(2.16 \mathrm{E}-04)\end{array}$ & $\begin{array}{c}4.04 \mathrm{E}-04 \\
(2.72 \mathrm{E}-04)\end{array}$ \\
\hline Male & $\begin{array}{c}0.025 * * * \\
(0.002)\end{array}$ & $\begin{array}{c}0.058 * * * \\
(0.003)\end{array}$ \\
\hline Age & $\begin{array}{c}0.116 * * * \\
(0.007)\end{array}$ & $\begin{array}{c}0.002 \\
(0.009)\end{array}$ \\
\hline Age Squared & $\begin{array}{c}-2.96 \mathrm{E}-03 * * * \\
(2.29 \mathrm{E}-04)\end{array}$ & $\begin{array}{l}\text { 7.30E-05 } \\
(1.95 \mathrm{E}-04)\end{array}$ \\
\hline Family size & $\begin{array}{c}-0.006 * * * \\
(0.001)\end{array}$ & $\begin{array}{c}-0.005 * * * \\
(0.001)\end{array}$ \\
\hline Divorced & $\begin{array}{c}0.039 * * * \\
(0.018)\end{array}$ & $\begin{array}{l}-0.002 \\
(0.005)\end{array}$ \\
\hline Married & $\begin{array}{c}-0.035^{* * *} * \\
(0.003)\end{array}$ & $\begin{array}{c}-0.067 * * * \\
(0.003)\end{array}$ \\
\hline Widowed & N/A & $\begin{array}{c}0.010 \\
(0.030)\end{array}$ \\
\hline Percentage of state reporting arrest data & $\begin{array}{l}-0.011 \\
(0.097)\end{array}$ & $\begin{array}{l}-0.019 \\
(0.015)\end{array}$ \\
\hline African-American & $\begin{array}{c}-0.014 * * * \\
(0.003)\end{array}$ & $\begin{array}{c}-0.008 * * \\
(0.004)\end{array}$ \\
\hline Hispanic & $\begin{array}{c}-0.016^{* * * *} \\
(0.003)\end{array}$ & $\begin{array}{c}-0.054 * * * \\
(0.003)\end{array}$ \\
\hline Other race/ethnicity & $\begin{array}{c}-0.034 * * * \\
(0.003)\end{array}$ & $\begin{array}{c}-0.046 * * * \\
(0.004)\end{array}$ \\
\hline Real family income & $\begin{array}{c}-2.16 \mathrm{e}-07 * * * \\
(5.65 \mathrm{e}-08)\end{array}$ & $\begin{array}{c}-4.43 \mathrm{E}-07 * * * \\
(7.99 \mathrm{E}-08)\end{array}$ \\
\hline Student & $\begin{array}{c}-0.025 * * * \\
(0.004)\end{array}$ & $\begin{array}{c}-0.015 * * * \\
(0.004)\end{array}$ \\
\hline Education $<12$ years & $\begin{array}{c}0.022 * * * \\
(0.003)\end{array}$ & $\begin{array}{c}0.038 * * * \\
(0.005)\end{array}$ \\
\hline Some college education & $\begin{array}{c}0.000 \\
(0.004)\end{array}$ & $\begin{array}{c}-0.016 * * * \\
(0.003)\end{array}$ \\
\hline College graduate & $\begin{array}{l}-0.027 \\
(0.015)\end{array}$ & $\begin{array}{c}-0.038 * * * \\
(0.003)\end{array}$ \\
\hline Post-graduate education & N/A & $\begin{array}{c}-0.053^{* * *} * \\
(0.003)\end{array}$ \\
\hline MSA population $>1,000,000$ & $\begin{array}{c}0.013 * * \\
(0.004)\end{array}$ & $\begin{array}{c}0.011 * * \\
(0.005)\end{array}$ \\
\hline MSA population $250,000-1,000,000$ & $\begin{array}{c}0.010^{* * *} \\
(0.005)\end{array}$ & $\begin{array}{c}0.005 \\
(0.006)\end{array}$ \\
\hline Urban residence & $\begin{array}{l}-0.002 \\
(0.005)\end{array}$ & $\begin{array}{l}-0.011^{*} \\
(0.006)\end{array}$ \\
\hline Rural residence & $\begin{array}{c}-0.020 * * * \\
(0.004)\end{array}$ & $\begin{array}{c}-0.022 * * * \\
(0.005)\end{array}$ \\
\hline Interview conducted privately & $\begin{array}{c}0.006 * * \\
(0.003) \\
\end{array}$ & $\begin{array}{l}-0.005 \\
(0.004) \\
\end{array}$ \\
\hline
\end{tabular}




\section{REFERENCES}

American Chamber of Commerce Researchers Association. 1991-1997. Inter-City Cost of Living Index. Louisville, KY: American Chamber of Commerce Researchers Association.

Chaloupka, F.J., and A. Laixuthai. 1997. "Do Youths Substitute Alcohol for Marijuana? Some Econometric Evidence.” Eastern Economic Journal 23(3):253-276.

Chaloupka, F. J., and H. Wechsler. 1996. "Binge Drinking in College: The Impact of Price, Availability, and Alcohol Control Policies." Contemporary Economic Policy 14(4).

Chaloupka, F. J., R.L. Pacula, M.C. Farrelly, L.D. Johnston, P.M. O’Malley, and J.W. Bray. 1998. "Do Higher Cigarette Prices Encourage youth to Use Marijuana?" Working paper.

Coalition on Smoking OR Health. 1991-1995. State Legislated Actions on Tobacco. Washington, DC: Coalition on Smoking OR Health.

DiNardo, J., and T. Lemieux. 1992. "Alcohol, Marijuana, and American Youth: The Unintended Effects of Government Regulation.” NBER Working Paper 4122.

Drug Enforcement Administration Intelligence Division, U.S. Department of Justice. Various years. STRIDE Database. Washington, DC: U.S. Department of Justice.

Duan, N., W. G. Manning, Jr., C. N. Morris, and J. P. Newhouse. 1983. "A Comparison of Alternative Models for the Demand for Medical Care." Journal of Business \& Economic Statistics 1(2):115-126.

Evans, W.N., and M.C. Farrelly. 1998. “The Compensating Behavior of Smokers: Taxes, Tar, and Nicotine." The RAND Journal, 29(3):578-595.

Evans, W.N., M.C. Farrelly, and E. Montgomery. 1996. "Do Workplace Smoking Bans Reduce Smoking?" National Bureau of Economic Research, working paper series, \#5567.

Farrelly, M.C., and W.N. Evans. 1996. "State Clean Indoor Air Laws and Smoking Participation Among Workers." Dissertation, University of Maryland-College Park.

Hoyt, G.M., and F.J. Chaloupka. 1993. "Self-reported Substance Use and Survey Conditions: An Examination of the National Longitudinal Survey of Youth." Presented at the Western Economic Association annual meeting, Lake Tahoe, June 23.

Manning, W.G., L. Blumberg, and L.H. Moulton. 1995. "The Demand For Alcohol: Differential Response to Price." Journal of Health Economics 14(2):123.

Model, K. 1993. “The Effect of Marijuana Decriminalization on Hospital Emergency Drug Episodes: 1975-1978.” Journal of the American Statistical Association 88:423.

Pacula, R. 1998. "Does Increasing the Beer Tax Reduce Marijuana Consumption.” Journal of Health Economics 17:557-585. 
Saffer, F., and F.J. Chaloupka. 1998. "Demographic Differentials in the Demand for Alcohol and Illicit Drugs." National Bureau of Economic Research, working paper series, \#6432.

Substance Abuse and Mental Health Services Administration (SAMHSA). 1992. National Household Survey on Drug Abuse: Public Release Codebook 1991. Rockville, MD: U.S. Department of Health and Human Services.

Substance Abuse and Mental Health Services Administration (SAMHSA). 1994. National Household Survey on Drug Abuse: Public Release Codebook 1992. Rockville, MD: U.S. Department of Health and Human Services.

Thies, C.F., and C.A. Register. 1993. "Decriminalization of Marijuana and The Demand for Alcohol, Marijuana, and Cocaine.” The Social Science Journal 30(4):385-399.

Tobacco Institute. 1997. The Tax Burden on Tobacco: Historical Compilation 1993. Vol. 28. Washington, DC: Tobacco Institute.

Turner, C., J. Lessler, and J. Devore. 1992. "Effects of Mode of Administration and Wording on Reporting of Drug Use." In Survey Measurement of Drug Use: Methodological Studies. Rockville, MD: National Institute on Drug Abuse. 